\title{
AVALIAÇÃO MICROBIOLÓGICA DAS CONDIÇÕES DE LIMPEZA DOS CIRCUITOS DE VENTILAÇÃO MECÂNICA UTILIZADOS EM UM HOSPITAL UNIVERSITÁRIO
}

\section{MICROBIOLOGICAL EVALUATION OF THE CLEANING CONDITIONS OF THE MECHANICAL VENTILATION CIRCUITS USED IN UNIVERSITY HOSPITAL}

\section{EVALUACIÓN MICROBIOLÓGICA DE LAS CONDICIONES DE LIMPIEZA DE LOS CIRCUITOS DE VENTILACIÓN MECÁNICA UTILIZADOS EN UN HOSPITAL UNIVERSITARIO}

\author{
Wanessa Maria Santos ${ }^{1}$, Mônica Hitomi Okura², Gilberto Araújo Pereira ${ }^{3}$
}

\begin{abstract}
RESUMO
Objetivo: verificar a incidência de micro-organismos potencialmente patogênicos isolados antes e após os métodos de processamento dos circuitos respiratórios dos ventiladores mecânicos e analisar os resultados das hemoculturas dos pacientes traqueostomizados durante o período do estudo. Metodologia: estudo transversal, descritivo, com abordagem qualiquantitativa, realizado em um hospital público de ensino, do Sudeste do Brasil. Realizaram-se análises microbiológicas dos circuitos respiratórios reprocessados dos aparelhos de ventilação mecânica. Foram analisados os dados dos prontuários quanto aos seguintes aspectos: sexo do paciente, realização de traqueostomia, micro-organismos isolados e o perfil de resistência bacteriana ao antimicrobiano testado. Resultados: foi detectada a presença de bactérias nas diferentes etapas do estudo, sendo caracterizados como Staphylococcus aureus, Staphylococcus sp. coagulase negativa, Pseudomonas aeruginosa, Enterobacter cloacae, e Enterococcus. Conclusão: foi possível evidenciar a presença de contaminação bacteriana nas diferentes etapas do estudo e também a presença desses agentes nos exames de hemocultura.
\end{abstract}

Descritores: Respiração artificial; Contaminação de Equipamentos; Infecção Hospital.

\footnotetext{
${ }_{1}$ Mestre em Inovação Tecnológica, pelo Programa de Mestrado Profissional em Inovação Tecnológica da Universidade Federal do Triângulo Mineiro (PMPIT/UFTM). Possui especialidade em Análises clínicas. Graduada em biomedicina pela universidade federal do triangulo mineiro. Técnico de enfermagem da Universidade Federal do Triângulo Mineiro.

${ }^{2}$ Doutora (Engenharia de Alimentos). Professora titular da Universidade Federal do Triângulo Mineiro do curso de Engenharia de Alimentos, do Programa de Mestrado Profissional em Inovação Tecnológica e da Pós Graduação em Ciência e Tecnologia Ambiental.

${ }^{3}$ Estatístico. Doutor em Estatística. Professor Adjunto do Curso de Graduação em Enfermagem da UFTM, Uberaba (MG), Brasil
} 


\begin{abstract}
Objective: To verify the incidence of potentially pathogenic microorganisms isolated before and after mechanical ventilator respiratory circuit processing methods and to analyze the blood cultures results of tracheostomized patients during the study period. Methodology: Cross-sectional, descriptive study, with qualitative-quantitative approach, carried out in a public teaching hospital, in Southeastern Brazil. Microbiological analyzes of the reprocessed respiratory circuits of the mechanical ventilation apparatus were carried out. The data of the medical records were analyzed for the following aspects: patient gender, tracheostomy, isolated microorganisms and the bacterial resistance profile to the antimicrobial tested. Results: Staphylococcus aureus, Staphylococcus sp., Was detected in the different stages of the study. coagulase negative, Pseudomonas aeruginosa, Enterobacter cloacae, and Enterococcus. Conclusion: it was possible to evidence the presence of bacterial contamination in the different stages of the study and also the presence of these agents in blood culture tests.
\end{abstract}

Descriptors: Respiration; Artificial; Equipment Contamination; Cross Infection.

\title{
RESUMEN
}

Objetivo: verificar la incidencia de microorganismos potencialmente patógenos aislados antes y después de los métodos de procesamiento de los circuitos respiratorios de los ventiladores mecánicos y analizar los resultados de los hemocultivos de los pacientes traqueostomizados durante el período del estudio. Metodología: Estudio transversal, descriptivo, abordaje cualitativo cuantitativo, realizado en un hospital público, de Sudeste de Brasil. Se realizaron análisis microbiológicos de los circuitos respiratorios reprocesados de los aparatos de ventilación mecánica. Se analizaron los datos de los prontuarios en cuanto a los siguientes aspectos: sexo del paciente, realización de traqueostomía, microorganismos aislados y el perfil de resistencia bacteriana al antimicrobiano probado. Resultados: De las muestras analizadas, se detectó la presencia de bacterias en las diferentes etapas del estudio, siendo caracterizados como Staphylococcus aureus, Staphylococcus sp. coagulasa negativa, Pseudomonas aeruginosa, Enterobacter cloacae, y Enterococcus. Conclusión: fue posible evidenciar la presencia de contaminación bacteriana, en las diferentes etapas del estudio y también la presencia de esos agentes en los exámenes de hemocultura.

Descriptores: Respiración Artificial; Contaminación de Equipos; Infección Hospitalaria.

\section{Introdução}

A influência da inovação tecnológica na área da saúde tem se mostrado cada vez mais notória nos dias atuais, seja em termos de disponibilidade de equipamentos ou em novas técnicas assistenciais, refletindo em melhorias nas ações de saúde para a população. ${ }^{1}$

Não obstante, mesmo diante de todo progresso, alguns problemas antigos como as Infecções Relacionadas a Assistência à Saúde (IRAS) ainda se mostram prevalentes, promovendo um grande impacto frente à letalidade hospitalar, 
influenciando no período de internação e consequentemente nos custos referentes ao tratamento. $^{2}$

A ventilação mecânica (VM), ou também conhecida como suporte ventilatório, consiste em um método de apoio para o tratamento de pacientes com insuficiência respiratória aguda ou crônica agudizada, substituindo de forma total ou parcial a ventilação espontânea. Seu objetivo é propiciar a troca gasosa adequada, reduzir o trabalho da musculatura respiratória e atenuar a demanda metabólica dos pacientes que fazem uso da mesma. ${ }^{3}$

Para realização deste método, faz-se necessário o uso de ventiladores mecânicos que são compostos por um conjunto de acessórios como os circuitos respiratórios. Esses são constituídos de um conjunto de traqueias reutilizáveis que saem do aparelho de VM e levam gás oxigênio e ar comprimido em direção ao paciente que necessita de suporte. O processo de manipulação desses dispositivos abrange etapas desde sua utilização até seu retorno em condições ideais de reuso. ${ }^{3}$

A Sociedade Brasileira de Pneumologia e Tisiologia e a Associação de Medicina Intensiva Brasileira classificam os circuitos utilizados na VM como semicríticos, devido ao risco potencial de transmissão de infecções. Nesse sentido, a prevenção e o controle da transmissão de micro-organismos apresentam-se imprescindíveis para a saúde e segurança dos pacientes que necessitam de utilizar estes equipamentos. ${ }^{4}$

Dentre as principais medidas de prevenção, destaca-se o reprocessamento dos dispositivos utilizados na assistência hospitalar. Estes equipamentos devem estar em condições seguras e livres de micro-organismos viáveis antes de um próximo uso minimizando, assim, os riscos de contaminação. ${ }^{5}$

Os pacientes em VM pertencem a um grupo de risco aumentado para adquirir IRAS, ocasião em que os principais fatores predisponentes são basicamente: idade avançada, nível de consciência rebaixado, intubação e reintubação traqueal, condições imunitárias defasadas, uso de drogas imunossupressoras, tempo de VM maior que sete dias, estado nutricional debilitado, contaminação exógena, antibioticoterapia, colonização microbiana, cirurgia de tempo prolongado, aspiração do condensado contaminado dos circuitos do ventilador utilizado, aspirações de secreções contaminadas, 
colonização gástrica e aspiração da mesma. $^{6}$

A Pneumonia Associada à Ventilação Mecânica (PAV) trata-se da complicação infecciosa mais prevalente em pacientes que necessitam de suporte ventilatório. Os principais componentes para o diagnóstico da PAV à beira do leito levam em consideração uma combinação de achados como radiografia de tórax, sinais e sintomas clínicos, e exames laboratoriais. Estudo recente aponta que, além dos aparentes sinais clínicos, os pacientes com suspeita de infecção devem ser imediatamente submetidos a estudos microbiológicos. $^{7}$

Deste modo, a identificação precoce do patógeno pela análise microbiológica no sangue e em outros fluídos corporais tem valor preditivo frente ao diagnóstico, monitoramento e triagem dos agentes patogênicos, uma vez que o desenvolvimento da resistência dos microorganismos aos agentes antibacterianos revela ser um problema constante. Dentre os critérios laboratoriais, a confirmação microbiológica é de suma importância para a realização do tratamento adequado sendo realizada a partir do resultado de uma hemocultura positiva sem outro foco de infecção aparente, cultura positiva do líquido pleural, cultura do lavado bronco alveolar ou traqueal, exame histopatológico com evidência de infecção pulmonar, antígeno urinário e outros testes laboratoriais positivos para patógenos respiratórios. ${ }^{8}$

Diante da magnitude das IRAS, conhecer a microbiota $\mathrm{e}$ as principais fontes de infecção faz-se necessário para a prevenção e o controle de infecções relacionadas a assistência à saúde. Além disso, a investigação do processamento de dispositivos de terapia ventilatória, entre outros equipamentos médico-hospitalares, é um passo de extrema relevância, uma vez que as infecções associadas à VM têm alcançado números expressivos nas instituições hospitalares. ${ }^{9}$

Assim, o objetivo deste estudo é verificar a incidência de micro-organismos potencialmente patogênicos isolados antes e após os métodos de processamento dos circuitos respiratórios dos ventiladores mecânicos, além de analisar os resultados das hemoculturas dos pacientes que utilizaram ventilação mecânica durante o período do estudo. 


\section{MÉTODO}

Trata-se de um estudo descritivo com amostra não probabilística, transversal, com abordagem quali-quantitativa, em que a ocorrência do desfecho foi observada em um único intervalo de tempo, no período de setembro a novembro de 2017, em um hospital público de ensino do Sudeste do Brasil.

\section{Processamento dos circuitos e coleta das amostras}

O processamento dos circuitos respiratórios foi realizado de forma centralizada, no setor conhecido como Central de Equipamentos, na seguinte sequência: imersão em solução enzimática (segundo orientação do fabricante), limpeza manual e enxágue. Depois de limpas, as traqueias foram colocadas para escorrer e secar em caixas plásticas, submetidas ao ar comprimido e posteriormente encaminhadas para uma empresa terceirizada para serem esterilizadas em óxido de etileno. Durante as etapas operacionais dos métodos de processamento não houve interferência dos pesquisadores.

A coleta das amostras, considerando os circuitos prontos para uso, foi realizada dentro da área restrita dos equipamentos e dispositivos esterilizados, por meio de técnica asséptica com prévio preparo das superfícies, o que afasta a possibilidade de contaminação no momento da coleta.

Para as análises quantitativas e qualitativas, as coletas das amostras foram divididas em três etapas, de acordo com os métodos de processamento utilizados pela instituição pesquisada. Foram sujeitos da amostra, por conveniência, um total de 276 amostras (30 amostras da análise quantitativa e 246 da análise qualitativa), de acordo com a demanda de reuso desses equipamentos e dispositivos.

A etapa 1 representa o grupo de amostras obtidas dos circuitos dos ventiladores mecânicos provenientes das unidades assistenciais, que foram utilizados nos pacientes extubados devido ao procedimento de desmame ou óbito. As coletas dos circuitos foram realizadas no ramo expiratório e a análise procedeu-se de forma asséptica, assegurando a esterilidade das amostras. Após os circuitos serem submersos em solução enzimática e secos por ar comprimido, inicia-se a etapa 2, quando se coletaram 82 amostras.

Nessas etapas, um total de 82 equipamentos foram recebidos no local conhecido como expurgo ou área suja, e o 
controle dos ventiladores mecânicos incluídos na pesquisa foi realizado a partir do número de patrimônio atribuído pela instituição a fim de evitar possíveis trocas, uma vez que o mesmo equipamento pode entrar no ciclo de reuso por diversas vezes.

Para esse procedimento, $50 \mathrm{ml}$ de solução salina tamponada a $0,1 \%$ esterilizada foram adicionados no ramo do circuito. Executou-se homogeneização três vezes na tubulação e, em seguida, coletouse num tubo Falcon esterilizado e transportou-se ao laboratório.

Posteriormente, os circuitos foram encaminhados para uma empresa terceirizada responsável pela esterilização em óxido de etileno. Após o retorno dos equipamentos e dispositivos, iniciou-se a etapa 3. Nessa etapa, realizou-se coleta em dois momentos distintos: (1) após abertura do pacote estéril (41 coletas); (2) após a montagem do circuito nos ventiladores mecânicos (41 coletas) para futura liberação às unidades assistenciais, totalizando 82 amostras. Durante essa etapa os circuitos utilizados no estudo foram encaminhados para um novo ciclo de processamento.

\section{Análise microbiológica qualitativa}

No laboratório, as amostras em solução salina foram plaqueadas, utilizando a técnica de semeadura qualitativa em meio de cultura ágar Mueller-Hinton e incubadas a $37^{\circ} \mathrm{C}$ por 48 horas. Em seguida, foram isoladas cinco colônias diferentes de cada placa e inoculadas em eppendorfs contendo $1 \mathrm{ml}$ de ágar Brain Heart Infusion (BHI), os quais foram incubados a $37^{\circ} \mathrm{C}$ por 24 horas.

As amostras com detecção de crescimento microbiano foram isoladas em ágar sangue e aquelas que apresentaram crescimento foram caracterizadas macro e microscopicamente (coloração de Gram). Para a identificação de bactérias Gram positivas foram realizados os testes de catalase e de coagulase. No caso de Gramnegativas, foram empregados procedimentos bioquímicos diretos como motilidade, Indol e sulfato, Meio Tríplice Açúcar Ferro (TSI), Ureia e Citrato.

\section{Análise dos dados}

A fim de analisar a eficiência dos métodos de processamento dos circuitos da ventilação mecânica foi realizado um estudo quantitativo, baseado na técnica de 
inoculação em profundidade (técnica Pourplate), em 10 amostras coletadas em cada etapa, totalizando 30 amostras. Para o cálculo da eficiência foi utilizada a seguinte Equação (Equação 1) ${ }^{10}$, em que X inicial é a somatória da contagem de Unidade Formadora de Colônias (UFC) presente nos circuitos antes da aplicação do detergente enzimático e $\mathrm{X}$ final é a somatória da contagem de UFC que ainda estava presente nos circuitos após a aplicação do detergente enzimático. O detergente utilizado na instituição pesquisada (Indazyme 6 plus - Indalabor®) é composto por enzimas lipolíticas (lipase), enzimas proteolíticas (protease, peptidase) e enzimas amilolíticas (carboidrase, alfaamilase e celulase).

$$
\text { Eficiência }(\%)=\frac{100 \times(X \text { inicial }-X \text { final })}{X \text { inicial }}
$$

\section{Análise dos prontuários}

O método de assistência ventilatória realizado em diferentes unidades de tratamento do hospital forneceu informações importantes sobre o perfil epidemiológico dos pacientes durante o período de tratamento. Para isso, foram utilizados dados contidos nos prontuários dos pacientes, extraídos do Serviço de Arquivo Médico e Estatístico e do Banco de Dados do Laboratório de Análises Clínicas e Anatomia, sem envolvimento direto do paciente. Para a composição das amostras deste estudo foram selecionados os indivíduos que realizaram hemocultura no período estudado e realizada a análise retrospectiva dos prontuários, sendo $\mathrm{o}$ número amostral determinado por amostragem não probabilística (conveniência). Os pacientes não foram monitorados quanto à presença de PAV, sendo que o resultado de hemocultura deste estudo não reflete no seu possível diagnóstico.

A análise realizada envolveu os seguintes dados: sexo do paciente, realização de traqueostomia (TQT), microorganismos isolados e o perfil de resistência bacteriana ao antimicrobiano testado.

\section{Análise estatística}

A análise estatística foi realizada por meio da distribuição de frequências absolutas e percentuais para variáveis nominais e para as variáveis numéricas 
discretas. A análise descritiva foi realizada por meio do programa software GraphPad Prism. O teste de Kolmogorov-Sminorv com Dallal-Wikinson-Liliefor foi aplicado para verificar se os dados seguiam distribuição normal ou não normal. Para os dados não normais, aplicou-se o teste não paramétrico de Friedman-Pareado. O nível de significância estabelecido foi de $5 \%$, ou seja, $\mathrm{p}<0,05$.

O projeto foi aprovado pelo Comitê de Ética em Pesquisa da Universidade Federal do Triângulo Mineiro sob o número 2.655.145/2018 e autorizado pela Gerência de Ensino e Pesquisa.

\section{RESULTADOS}

Das amostras referentes à abordagem qualitativa, 45,12\% (37/82) apresentaram um crescimento positivo antes de se iniciar o método de processamento (etapa 1). Após processamento em solução enzimática (etapa 2), 28,04\% apresentaram crescimento bacteriano (23/82). E após serem esterilizados por óxido de etileno (etapa 3), 13,41\% apresentaram crescimento positivo (11/82) (Figura 1A). No total, 198 micro-organismos foram isolados, sendo que 125 amostras $(63,13 \%)$ foram identificadas como cocos Grampositivos, 61 amostras (30,81\%) como bacilos Gram-negativos não fermentadores e 12 amostras (6,06\%) como pertencentes à família Enterobacteraceae (Figura 1B).

Figura 1 - Distribuição da frequência de amostras positivas e negativas (A), e percentual de micro-organismos isolados de culturas positivas do ramo expiratório dos circuitos (B), encontrados nas diferentes etapas analisadas. 


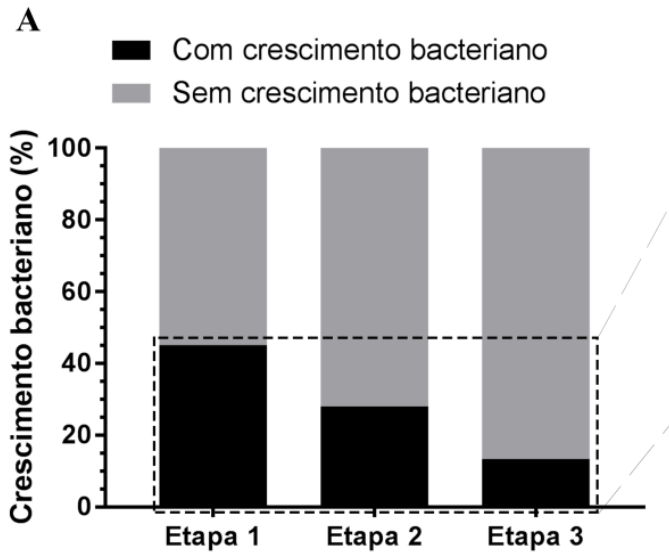

$\mathrm{Na}$ etapa 1, das 113 amostras positivas coletadas, $6,19 \%$ apresentaram positividade para

Staphylococcus aureus, 46,9\% para Staphylococcus sp. coagulase negativa, $38,05 \%$ para Pseudomonas aeruginosa e 8,85\% para Enterobacter cloacae. $\mathrm{Na}$ etapa 2, das 74 amostras positivas, podemos observar uma maior variação da população bacterina em relação às demais etapas, com $6,76 \%$ de positividade para Staphylococcus aureus, 39,19\% para Staphylococcus sp. coagulase negativa,
B

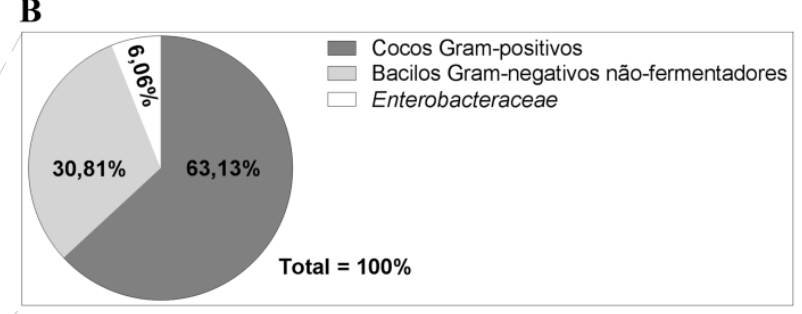

24,32\% para Pseudomonas aeruginosa, $14,86 \%$ para Enterobacter cloacae e $14,86 \%$ para Enterococcus. Por fim, na etapa 3, das 11 amostras positivas encontradas, é possível observar positividade de 9,09\% para Staphylococcus aureus e para Enterobacter cloacae e $81,82 \%$ para Staphylococcus sp. coagulase negativa. É notória a alta prevalência de Staphylococcus sp. coagulase negativa $(45,96 \%)$, assim como o padrão de positividade para Staphylococcus aureus nas três etapas analisadas (Figura 2). 
Figura 2 - Frequência (\%) das amostras positivas do ramo expiratório dos circuitos, para cada agente etiológico isolados durante a etapa 1,2 e 3.

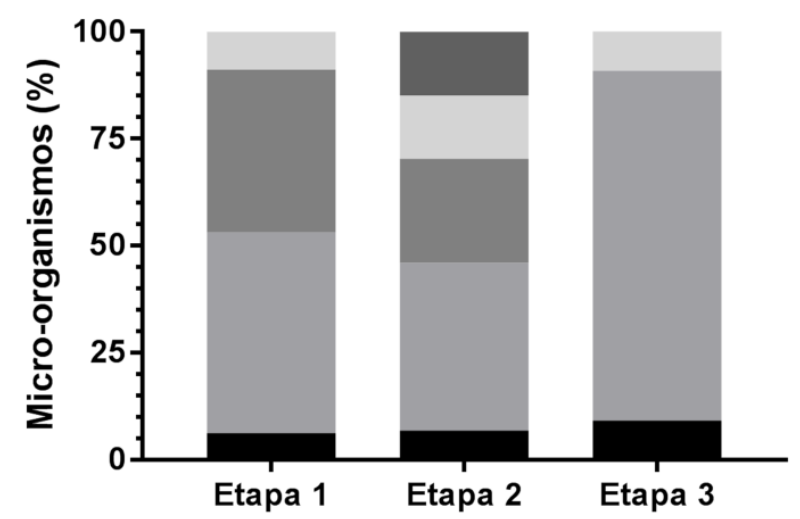

- Enterococcus

- Enterobacter cloacae

- Pseudomonas aeruginosa

- Staphylococcus sp. coagulase negativa

- Staphylococcus aureus

Avaliando de forma quantitativa a carga microbiana nas três etapas analisadas, é possível observar uma redução significativa no número de colônias isoladas $(\mathrm{UFC} / \mathrm{mL})$ entre a etapa 1 e os isolados da etapa 2 dos circuitos de VM reduzindo 70,9\%. Essa redução se mostra mais expressiva quando realizada a comparação entre a etapa 1 e a etapa 3, reduzindo $99,9 \%$ da carga microbiana inicial. Com base nos resultados dos valores máximos de micro-organismos encontrados em cada etapa, nota-se a influência do processamento dos equipamentos frente à carga microbiana presente nos circuitos analisados, sendo: etapa 1 de $3,3 \times 10^{6}$ UFC, etapa 2 de $9,6 \times$ $10^{5}$ UFC e durante a etapa 3 foi de $8,0 \times$ $10^{2}$ UFC. 
Figura 3 - Análise quantitativa do número de Unidades Formadoras de Colônia por mililitro (UFC/mL) entre as etapas antes e após o tratamento dos circuitos respiratórios com solução enzimática. Comparação estatística realizada pelo teste pareado de Fredman.

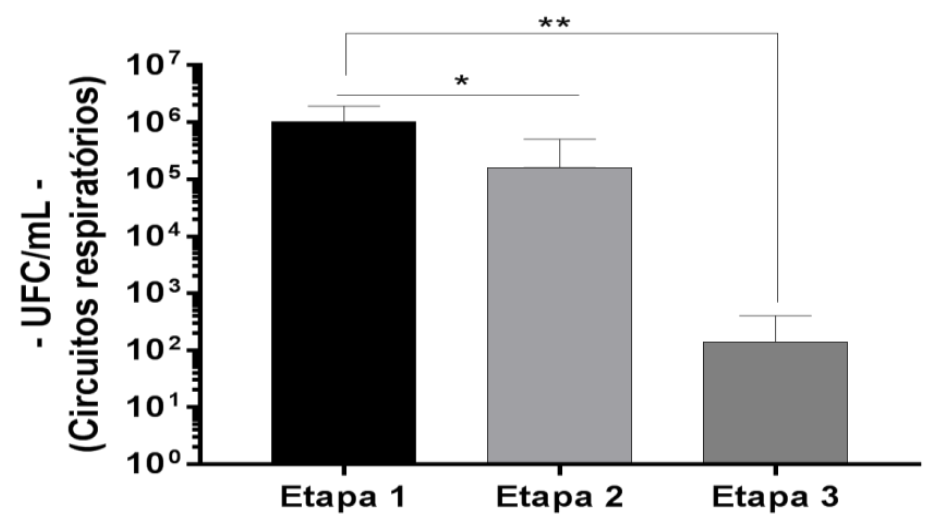

A análise correspondente à etapa dos resultados dos exames de hemocultura obtidos de pacientes que realizaram o procedimento de TQT foi constituída por 17 prontuários, sendo $9(52,94 \%)$ do sexo feminino e $8(47,06 \%)$ do sexo masculino. ocasião em que se observa uma maior frequência de amostras positivas de hemoculturas por Klebsiella pneumoniae e Enterobacter cloacae, seguida de Staphylococcus aureus e Staphylococcus coagulase negativa.

$\mathrm{Na}$ figura 4 estão apresentados todos os micro-organismos isolados e analisados,

Figura 4 - Distribuição dos micro-organismos isolados em hemocultura de pacientes. N.D: Não detectado. Uberaba-MG, setembro a novembro de 2017.
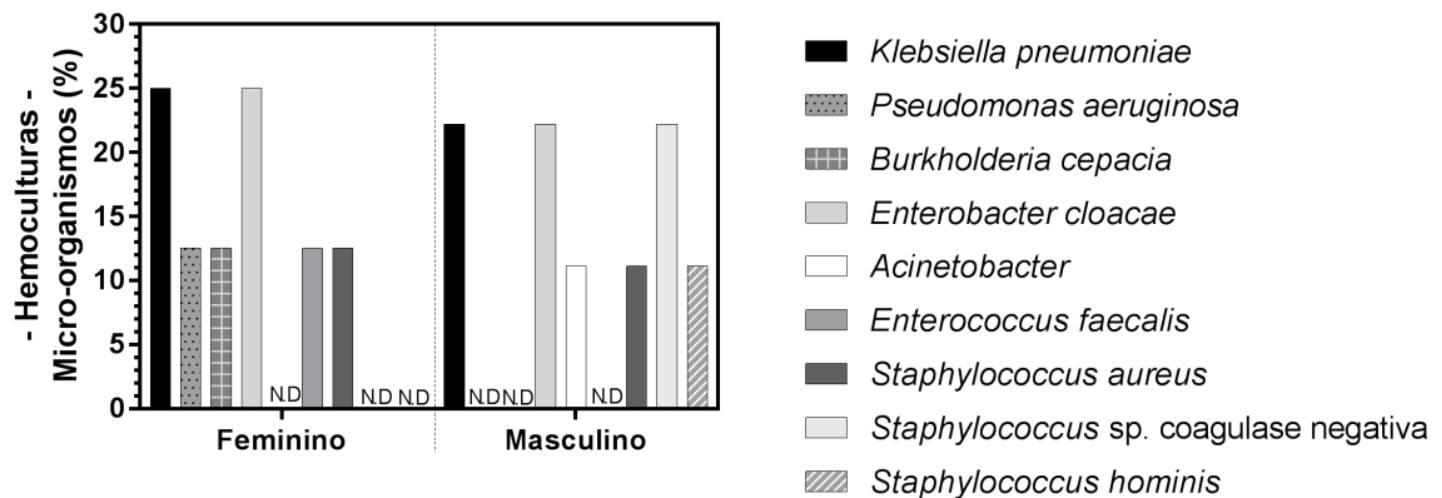
Em relação à sensibilidade microbiana, a figura 5 representa o perfil apresentado pelos micro-organismos Staphylococcus coagulase negativa e Staphylococcus aureus, ambos do grupo das bactérias gram-positivas, e o perfil de Acinetobacter, pertencente ao grupo de bactérias gram-negativas, sobre os quais os agentes antimicrobianos oxacilina, meropenem e o ciprofloxacina foram capazes de atuar. É possível observar que o Acinetobacter ssp. apresentou sensibilidade aos agentes antibacterianos do grupo dos beta-lactâmicos, quinolônico sintético e ao carbapenêmico meropenem, propiciando uma grande probabilidade de resposta ao tratamento devido ao bom perfil farmacocinético/dinâmico dessas classes.

Figura 5 - Percentual de sensibilidade dos micro-organismos ao exame de antibiograma de pacientes traqueostomizados. Uberaba-MG, setembro a novembro de 2017.

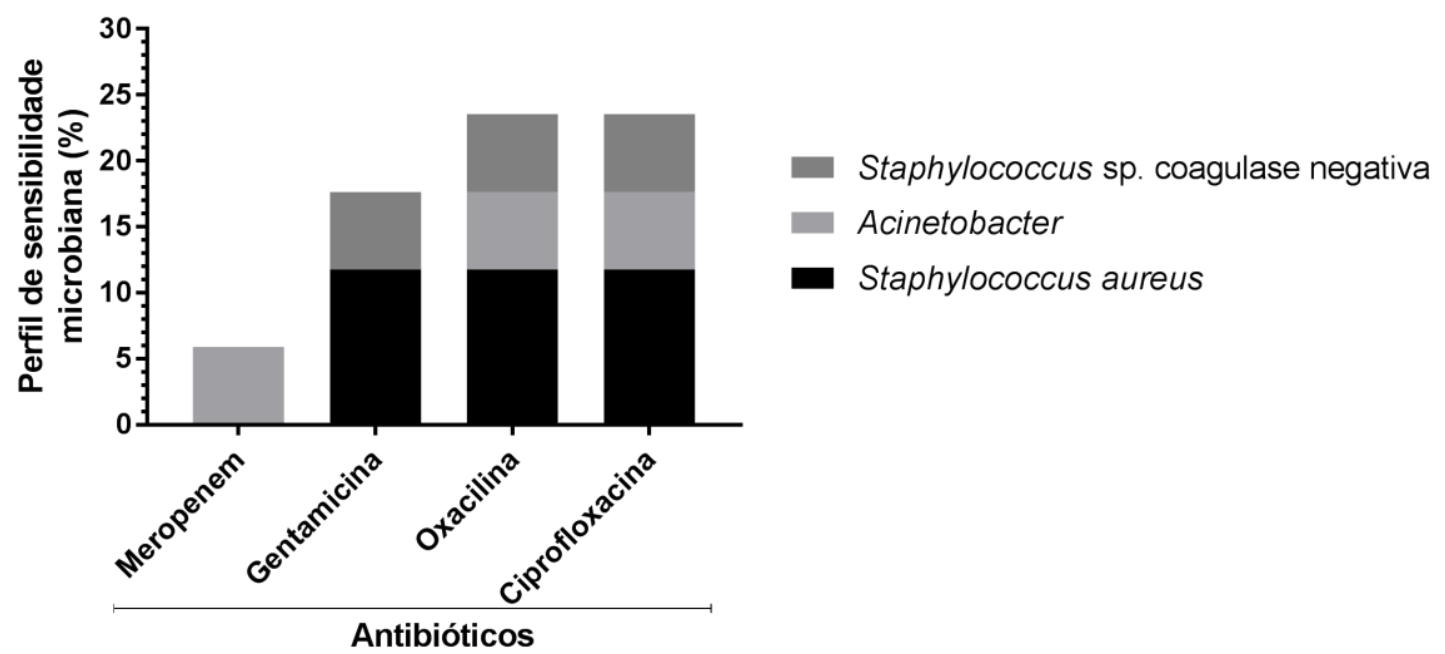

\section{DISCUSSÃO}

É estabelecido o fato de que as superfícies dos dispositivos médicos são uma fonte crescente de infecções nosocomiais em hospitais e clínicas de todo o mundo. 5 Os fatores envolvidos nesse processo se relacionam a falhas humanas ou mecânicas que possam ocorrer durante o processamento, implicando 
possível comprometimento na esterilidade dos dispositivos propiciando, assim, um aumento no risco de casos de infecção.

Trabalhos já relataram que os pacientes que necessitam de VM por um longo período de tempo são confrontados com uma alta probabilidade de contrair PAV. ${ }^{11} \mathrm{O}$ tubo endotraqueal utilizado na VM fornece uma superfície propícia para as bactérias aderirem e formarem um biofilme, além de permitir a formação de condensados dentro dos circuitos respiratórios, os quais podem sofrer rápida colonização por patógenos, além de contribuírem para a resistência a medicamentos antibacterianos. ${ }^{11-12}$

O estudo evidenciou a presença de contaminação bacteriana em todas as etapas de análise dos circuitos respiratórios, além de confirmar a presença desses agentes nos exames de hemocultura realizados nos pacientes que foram submetidos ao procedimento de traqueostomia. Durante o estudo, algumas traqueias apresentaram a presença de matéria orgânica (secreção e/ou sangue) após etapa da limpeza manual (etapa 2). Esse achado corrobora os da literatura que ressaltam a importância da etapa de limpeza de maneira vigorosa para que a ação do desinfetante não seja prejudicada. $^{9,13}$

Para uma melhor eficácia na qualidade do processo, após a limpeza, o enxágue exaustivo e rigoroso em água corrente deve ocorrer utilizando torneiras com bico de pressão para remoção das sujidades e matérias orgânicas, antes que ocorra o ressecamento do material na superfície interna do circuito. Essa ação reduz o número de contaminações microbianas e, consequentemente, a formação de biofilme. ${ }^{13}$

Em relação aos resultados obtidos na etapa 3, o método quantitativo verificou a presença de carga microbiana de até $8,0 \times$ $10^{2}$ UFC. Esses resultados assemelham com o estudo de Silva e Pinto ${ }^{14}$ em que, mesmo após o processo de limpeza e esterilização dos equipamentos e dispositivos, os autores verificaram a presença de carga microbiana de até $10^{3}$ UFC/mL. Esse mesmo resultado foi também confirmado de modo macroscópico, pelo crescimento microbiano característico nos testes de esterilidade. Os autores concluíram que apesar de redução logarítmica da carga microbiana os tubos não apresentaram ausência de carga microbiana e endotoxinas. 
Em relação às orientações e recomendações específicas da Agência Nacional de Vigilância Sanitária (ANVISA) referentes ao tempo em que o circuito deve ficar montado no equipamento aguardando a internação do paciente ainda não estão bem estabelecidas, fato que possibilitaria uma melhor prevenção e controle das infecções relacionadas a assistência à saúde. ${ }^{4}$ Contudo, as análises quantitativas das amostras da etapa 3 encontradas neste estudo referem-se a quantidade de dias em que os circuitos estéreis ficaram montados nos VM: 05 dias, 10 dias e 30 dias, sendo encontrados valores referentes às cargas microbianas de $2,10 \times 10^{2} \mathrm{UFC} / \mathrm{ml}, 3,80 \times$ $10^{2} \mathrm{UFC} / \mathrm{ml}$ e $8,00 \times 10^{2} \mathrm{UFC} / \mathrm{ml}$ respectivamente. As montagens de tais circuitos foram realizadas com técnica asséptica, conforme normas do setor Central de Equipamento. Em teoria, sugerem que quanto maior o tempo de montagem dos circuitos estéreis no ventilador mecânico, para aguardar o momento de conectar no paciente, maiores serão os riscos de contaminação dos circuitos.

\section{CONCLUSÃO}

A avaliação da eficácia do método de processamento mostrou uma redução na quantidade de matéria orgânica total presente nos circuitos, no entanto, evidenciou que os circuitos dos ventiladores mecânicos podem abrigar bactérias, conduzindo eventualmente, à contaminação cruzada. Foram identificados micro-organismos comuns nas amostras de hemocultura e nas amostras dos circuitos, reforçando a importância da aquisição de uma política intra-hospitalar incisiva no combate à infecção, de forma ampla, a todos os prestadores de serviço hospitalar.

Medidas preventivas são essenciais, uma vez que a implantação de estratégias de controle e padronização e o treinamento de condutas para a assistência aos pacientes de risco minimizam a transmissão de micro-organismos pela da redução de colonização desses e dos seus reservatórios.

O trabalho desenvolvido em uma Central de Equipamento apresenta uma importante relevância frente ao controle de $\mathrm{IH}$, já que as atividades desenvolvidas nessa unidade contribuem para a redução de eventos adversos. Dessa forma, os 
principais pontos levantados neste estudo possibilitaram que os enfermeiros da unidade fossem capazes de refletir sobre os problemas relacionados com o método de processamento dos circuitos de ventilação mecânica e, consequentemente, organizassem um plano de ação com objetivos de melhorar e resolver tais problemas.

Destaca-se que este estudo teve como fator de limitação o não monitoramento do tempo de uso dos circuitos de acordo com o ciclo de processamento. Ainda assim, permitiu verificar que o controle de qualidade do processamento dos circuitos de ventilação mecânica somente é obtido a partir do monitoramento das etapas que envolvem a limpeza, desinfecção e a esterilização. Desse modo, contribui-se para a melhoria do cuidado indireto na Central de Equipamentos e nas demais áreas de assistência ao paciente, atentando, assim, para a sua importância no favorecimento do cuidado direto.

\section{REFERÊNCIAS}

1-Pires DE, Matos E, Azambuja EP, Trindade, LL, Scherer, Magda DA. New Technologies And Workloads Of Health Care Professionals. Repository of
Technische Universität Berlin [Internet]. 2014 [citado em 14 fev 2018]; 1-13. Disponível em:

https://pdfs.semanticscholar.org/7fa9/2859 0fa85b5c057ff83d8ea7c53aabb53ac4.pdf 2-Padoveze MC, Fortaleza, CMCB. Infecções relacionadas à assistência à saúde: desafios para a saúde pública no Brasil. Rev Saúde Públ. [Internet] 2014 [citado em 11 jul 2018]; 48(6):995-1001. Disponível em:

http://www.scielo.br/pdf/rsp/v48n6/pt_003 4-8910-rsp-48-60995.pdf.

3-Melo AS, Almeida RMS, Oliveira CD. A mecânica da ventilação mecânica. Rev Méd Minas Gerais [Internet] 2014 [citado em 14 abr 2018]; 24:43-8. Disponível em: rmmg.org/exportarpdf/1679/v24s8a07.pdf.

4- Agência Nacional de Vigilância Sanitária (Brasil). Gerência Geral de Tecnologia em Serviços de Saúde. Gerência de Vigilância e Monitoramento em Serviços de Saúde. Medidas de prevenção de infecção relacionada à assistência à saúde [Internet]. Brasília, DF: ANVISA; 2017. (Segurança do paciente e qualidade em serviços de saúde) [citado em 5 fev 2018].

Disponível em: http://portal.anvisa.gov.br/documents/3385 2/3507912/Caderno+4+-

+Medidas+de+Preven\%C3\%A7\%C3\%A3 o+de+Infec\%C3\% A7\%C3\% A3o+Relacion ada+\% C

$3 \% \mathrm{~A} 0+$ Assist $\% \mathrm{C} 3 \% \mathrm{AAncia}+\% \mathrm{C} 3 \% \mathrm{~A} 0+\mathrm{S}$ a\%C3\%BAde/a3f23dfb-2c54-4e64881 cfccf9220c373.

5-Geilich BM; Webster TJ. Reduced adhesion of Staphylococcus aureus to $\mathrm{ZnO} / \mathrm{PVC}$ nanocomposites. Int $\mathrm{J}$ Nanomedicine [Internet] 2013 [citado em 23 fev 2018]; 8:1177-84. Disponível em: https://www.dovepress.com/reducedadhesion-of-staphylococcus-aureus- 
toznopvc-nanocomposites-peer-reviewedarticle-IJN.

6-Chicayban LM, Terra ELVS, Ribela JS, Barbosa PF. Bundles de prevenção de pneumonia associada à ventilação mecânica: a importância da multidisciplinaridade. Persp Online: biol \& saúde [Internet] 2017 [citado em 20 out 2017]; 7(25):25-35. Disponível em: http://www.seer.perspectivasonline.com.br/ index.php/biologicas_e_saude/article/view/ 1200/9

34.

7- Mota ÉC, Oliveira SP, Silveira BRM, Silva PLN, Oliveira AC. Incidência da pneumonia associada à ventilação mecânica em unidade de terapia intensiva. Medicina (Ribeirão Preto) [Internet] 2017 [citado em 14 jul 2018]; 50:39-46. Disponível em: http://revista.fmrp.usp.br/2017/vol50n1/A O5-Incidencia-da-pneumonia-associadaaventilacao-mecanica-em-UTI.pdf. 8- Dalmora CH, Deutschendorf C, Nagel F, Santos RP, Lisboa T. Definindo pneumonia associada à ventilação mecânica: um conceito em (des) construção. Rev Bras Ter Intensiva [Internet] 2013 [citado em 28 nov 2017]; 25(2):81-6. Disponível em: http://www.scielo.br/pdf/rbti/v25n2/v25n2 a04.pdf.

9- Santos MVL, Costa JA. Processamento de artigos para terapia ventilatória: revisão da literatura nacional. Rev SOBECC [Internet] 2014 [citado em 14 jul 2018]; 87-91. Disponível em: http://www.sobecc.org.br/arquivos/artigos/ 2015/pdfs/site_sobecc_v19n2/05_sobecc_v 19n2.p df.

10-Buturi EP, Hort AA, Bona E, Tanamati AAC, Gonçalves $\mathrm{OH}$. Avaliação da eficiência de detergente enzimática na remoção de lipídios presentes em embalagens de produtos cárneos.
REBRAPA [Internet] 2014 [citado em 23 jul 2018]; 5(3):8-15. Disponível em: https://www.researchgate.net/publication/2 87601474_Evaluation_of_enzymatic_deter gent_ef

ficiency_in_removing_lipids_from_meat_ package/download.

11-Caratto V, Ball L, Sanguineti E, Insorsi A, Firpo I, Alberti S. et al. Atividades antibacteriana de tubos endotraqueais revestidos com dióxido de titânio padrão e dopados com nitrogênio: um estudo in vitro. Rev Bras Ter Intensiva [Internet] 2017 [citado em jul 2018]; 29(1):55-62. Disponível em: http://www.scielo.br/pdf/rbti/v29n1/0103507X-rbti-2901-0055.pdf.

12- Alcoforado L, Paiva D, Silva FS, Galvão AM, Galindo Filho V, Brandão DC et al. Trocador de calor e umidade:

proteção contra infecções pulmonares? Estudo piloto. Fisioter Pesqui. [Internet] 2012 [citado em 10 jan 2018]; 19(1):57-62. Disponível em:

http://www.scielo.br/pdf/fp/v19n1/11.pdf. 13-Carrara D, Shirahige CA, Braga ACPV, Ishioka S, Sakai P, Takeiti MH et al. A desinfecção de endoscópios com ácido peracético por dez minutos é efetiva? Rev SOBECC [Internet] 2013 [citado em 23 jan 2018]; 18(4):38-46. Disponível em: http://www.sobecc.org.br/arquivos/artigos/ 2014/pdfs/revisao-

deleitura/Ano18_n4_out_dezet2013-6.pdf. 14-Silva MV, Pinto TJA. Reutilização simulada de produtos médico-hospitalares de uso único, submetidos à esterilização com óxido de etileno. Rev Bras Cienc Farm. [Internet] 2005 [citado em 20 jan 2019]; 41(2):181-9. Disponível em: http://www.scielo.br/pdf/rbcf/v41n2/28037 .pdf.

RECEBIDO: 04/04/2019

APROVADO: 08/10/2019

PUBLICADO: $12 / 2019$ 